\title{
Methylmercury Induced Apoptosis of Human Neuroblastoma Cells Through the ROS Mediated Caspase and PARP/AIF Dependent Pathways
}

\section{Shanshan Hou}

Jilin University

Xiayu Zhang

Jilin University

\section{Xiaofan Ning}

Jilin University

Hao Wu

Jilin University

Xinyue Li

Jilin University

Kai Ma

Jilin University

Huifang Hao

Jilin University

Chunping Lv

Jilin University

Chunrui Li

Jilin University

Zhongjun Du

Shandong First Medical University

Haiying Du

Jilin University

Minghua Jin ( $\nabla_{\text {jinmh@jlu.edu.cn ) }}$

Jilin University https://orcid.org/0000-0002-2120-2977

\section{Research Article}

Keywords: Methylmercury, Neurotoxicant, ROS, PARP, AIF, Caspase

Posted Date: August 25th, 2021

DOl: https://doi.org/10.21203/rs.3.rs-831749/v1 
License: (c) (i) This work is licensed under a Creative Commons Attribution 4.0 International License. Read Full License 


\section{Abstract}

Methylmercury (MeHg) is an environmental neurotoxic substance, which can be absorbed by the human body through the digestive tract, and easily cross the blood-brain barrier, causing irreversible damage to the human central nervous system. Reactive oxygen species (ROS) are involved in various ways of intracellular physiological or pathological processes including neuronal apoptosis. The current studies attempted to explore the role of ROS-mediated PARP/AIF apoptosis signal in the process of MeHg inducing human neuroblastoma cells (SH-SY5Y) death. Here, the present studies found that SH-SY5Y cells underwent apoptosis in response to $\mathrm{MeHg}$, which was accompanied by increased the levels of ROS and calcium ion, and the activation of caspase cascades and poly ADP-ribose polymerase (PARP). The decrease in ROS levels significantly reduced the expression of these proteins and the rate of apoptosis. Inhibition of caspase pathway can reduce the rate of apoptosis, but can not prevent the occurrence of apoptosis. Furthermore, inhibition of PARP signaling can significantly reduce the apoptosis rate and the expression of caspase pathway related proteins. Collectively, these results indicated that ROS mediated activation of caspase pathway and PARP / AIF signaling pathway are involved in MeHg induced apoptosis, and there is a certain relationship between the two pathways.

\section{Introduction}

Methylmercury $(\mathrm{MeHg})$ is a neurotoxic environmental pollutant, produced by the transformation of mercury by microorganisms in the environment, is also the most toxic compound of mercury. The occupational exposure to mercury in "three wastes" namely air, water and soil, as well as the impact on food chains, have become public health issues of close concern (Nogara et al., 2019; Zhu et al., 2018). Due to the fat solubility of $\mathrm{MeHg}$, it can pass through the blood-brain barrier and accumulate in brain cells, causing serious neurological damage symptoms such as disturbance of perception, dyskinesia, narrowing of visual field and so on (Cariccio et al., 2019). In the 1950s, the outbreak of Minamata disease in Japan made people realize the neurotoxicity of MeHg for the first time (Koos and Longo, 1976). Although more than half a century has passed, the molecular mechanism of its neurotoxicity still needs further study.

Studies have shown that the mechanism of neurotoxicity induced by MeHg is related to the level of ROS. Excessive ROS is produced in the process of mitochondrial electron transfer chain in the brain during MeHg poisoning (Ishihara et al., 2016; Pereira et al., 2020). According to the literature, ROS can induce cell damage and organ dysfunction through a variety of ways, such as directly damaging DNA, causing lipid peroxidation, and changing protein function and activity (Kowalska et al., 2020; Srinivas et al., 2019). In 2014 , Zorov et al. believe that ROS mainly intensifies oxidative stress response through mitochondrial pathway, thus releasing more ROS, which is called ROS induced ROS release. ROS mediated mitochondrial dysfunction further causes apoptosis (Zorov et al., 2014), which have been associated with the several pathological conditions and the development of neurodegenerative disorders (Farina et al., 2011; Singh et al., 2019; Tarafdar and Pula, 2018). 
Mitochondria are one of the main targets of MeHg neurotoxicity. After low level of MeHg stimulation, mitochondria produce a large amount of ROS through mitochondrial permeability transition or intimal anion channels, followed by mitochondrial dysfunction, usually including mitochondrial calcium overload, release of cytochrome c (Cyt C) or apoptosis inducing factor (AIF) and activation of caspase dependent apoptosis pathway (Caito and Aschner, 2016; Lu et al., 2011; Polunas et al., 2011). AlF was identified as a molecule that could directly mediate cell apoptosis independent of caspase signaling pathway (Bano and Prehn, 2018; Madungwe et al., 2018). When the apoptotic process was triggered, AIF released translocating from mitochondria to nucleus and combined with chromosome DNA, resulting in chromosome aggregation and DNA fragmentation (Artus et al., 2010; Nedungadi et al., 2021). In the process of apoptosis, AIF was further hydrolyzed by calpain and cathepsin to form a $57 \mathrm{kD}$ soluble protein with the activity of inducing apoptosis, which was released into the cytoplasm to promote apoptosis. Poly ADP-ribose polymerase (PARP) is one of the important internal factors that leads to AIF release from mitochondria and transfer to nucleus (Yu et al., 2002). PARP can cause AIF release in nervous cells injury. Mitochondrial damage is the precondition of AIF release and the central link of PARP/AIF signaling pathway (Wang et al., 2016; Wang et al., 2009). ROS production is one of the necessary factors to induce mitochondrial damage and activate a variety of apoptotic pathways. Whether the inhibition of ROS affects the process of apoptosis needs to be further explored. Current studies have shown that apoptosis is one of the outcomes of MeHg cytotoxicity, which usually occurs through different pathways, including endoplasmic reticulum stress, mitochondrial dysfunction or death receptor pathway (Qi et al., 2015). PARP/AIF pathway is a new non classical apoptotic signal discovered in recent years. The role and mechanism of activation of PARP/AIF pathway in MeHg induced neuronal apoptosis and whether there is a relationship between PARP/AIF signal and classical apoptotic pathway are the problems to be solved in this study.

Taken together, in the present study, we tried to explore the role of ROS-mediated PARP/AIF apoptosis signal in MeHg induced SH-SY5Y cells death. To this aim, we investigated the production of ROS and the expression of apoptosis related proteins in SH-SY5Y cells induced by MeHg in vitro, and developed the potential mechanism of MeHg induced apoptosis through the use of inhibitors.

\section{Materials And Methods}

\subsection{Cell culture and treatment}

SH-SY5Y cells were purchased from Nanjing Keygen Biological Development Co., Ltd (Nanjing, China) and cultured in DMEM (Gibco, USA) high glucose medium supplemented with $10 \%$ fetal bovine serum (Bioind, Israel) and $1 \%$ Pen-Strep mixture (Gibco, USA) in a humidified incubator at $37^{\circ} \mathrm{C}$ and $5 \% \mathrm{CO}_{2}$ (Panasonic, Japan). The cells were washed with $0.25 \%$ trypsin and $0.02 \%$ EDTA-2Na (Invitrogen, USA) dissolved in phosphate buffered saline and seeded at the culture dish. After an incubation for $24 \mathrm{~h}$, the medium was changed and the cells were exposed to graded concentrations of MeHg (Merck, Germany) $(0,0.0001,0.001,0.01,0.1$ and $1.0 \mu \mathrm{g} / \mathrm{mL})$ for $3,6,12$ and $24 \mathrm{~h}$. 


\subsection{Cell viability assay}

The cells in logarithmic growth phase were seeded on 96 -well culture plate with the density of $5 \times 10^{4}$ cells/mL and $200 \mu \mathrm{L}$ per well for $24 \mathrm{~h}$. After 3, 6, 12 and $24 \mathrm{~h}$ of MeHg treatment in the 96-well culture plate, $20 \mu \mathrm{L}$ of MTT solution was added to each well. The MTT solution was prepared the concentration of $5 \mathrm{mg} / \mathrm{mL}$ in PBS. The plate was kept in an incubator at $37^{\circ} \mathrm{C}, 5 \% \mathrm{CO}_{2}$ for $4 \mathrm{~h}$. Then 150 $\mu \mathrm{L}$ DMSO (Amresco, USA) was added to each well to dissolve precipitates. The absorbance was measured at $490 \mathrm{~nm}$ by enzyme labeled instrument (BioTek, USA). Cell survival rate $=\left(\mathrm{OD}_{\text {sample }}{ }^{-}\right.$ $\left.O D_{\text {blank }}\right) /\left(O D_{\text {control }}-O D_{\text {blank }}\right) \times 100 \%$. The cells treated with different concentrations of $\mathrm{MeHg}$ were the sample groups, the cells treated with $0 \mu \mathrm{g} / \mathrm{mL}$ of MeHg were the control groups, and only $\mathrm{MeHg}$ with no cells were the blank groups. Probits of observed lethality percent values were used for the analysis of cell viability.

\subsection{Morphological changes of cells}

Cells in logarithmic growth phase were digested with $0.25 \%$ trypsin containing EDTA to prepare single cell suspension, and were inoculated in 24 -well culture dish for $24 \mathrm{~h}$ with the density of $1 \times 10^{5}$ cells $/ \mathrm{mL}$. After abandoning the culture medium, the cells were incubated with different concentrations of MeHg for $24 \mathrm{~h}$. Cell growth and morphological changes were observed using inverted fluorescence microscope (Leica, Germany).

\subsection{Detection of intracellular ROS and $\mathrm{Ca}^{2+}$}

The cells were pretreated with or without ROS inhibitor N-acetylcysteine (NAC) (Yeasen, China) $7.5 \mu \mathrm{M}$ for $1 \mathrm{~h}$, and then incubated with different concentrations of MeHg for $3 \mathrm{~h} .10 \mu \mathrm{M}$ DCFH-DA (Sigma, USA) probe was added to react for $30 \mathrm{~min}$ in the dark at $37^{\circ} \mathrm{C}$. Then the cells were washed twice with PBS and the ROS level was observed under fluorescence microscopy. After that, the culture medium was discarded, the cells were washed with $0.25 \%$ trypsin and centrifuged at $1000 \mathrm{rpm}$ for $5 \mathrm{~min}$, the cells were resuspended with PBS, and 10000 cells of each sample were collected by flow cytometry (FCM) to detect the average fluorescence intensity. For detecting the level of intracellular $\mathrm{Ca}^{2+}$, the cells were exposed to different concentrations of MeHg for $24 \mathrm{~h}$, and then incubated with $1.0 \mu \mathrm{M}$ Fluo-3 (Keygen, China) probe at $37^{\circ} \mathrm{C}$ for $40 \mathrm{~min}$. Finally, the unconjugated Fluo-3 probe was removed by PBS and the average fluorescence intensity of 10000 cells from each sample was detected by FCM.

\subsection{Apoptosis detection}

The quantification of apoptosis induced by MeHg in SH-SY5Y cells was detected using FCM with Annexin V-FITC/PI double staining assay. Briefly, the cells were exposed to different concentrations of $\mathrm{MeHg}$ for $24 \mathrm{~h}$ or pretreated with or without inhibitors NAC $7.5 \mu \mathrm{M}$, Z-VAD-FMK $50 \mu \mathrm{M}$ and olaparib $0.5 \mu \mathrm{M}$ for $1 \mathrm{~h}$ and $3 \mathrm{~h}, \mathrm{Z}$-VAD-FMK (Beyotime, China) is a pan caspase inhibitor and olaparib (Sigma, USA) is a PARP inhibitor, then separated and collected by trypsin, centrifuged at $1500 \mathrm{rpm}$ for $5 \mathrm{~min}$, washed and resuspended at approximately $1.0 \times 10^{6}$ cells $/ \mathrm{mL}$ in PBS. The following steps were using the Annexin V- 
FITC/PI apoptosis assay kit (Keygen, China) according to the manufacturer's instructions. The cells were stained with Annexin V-FITC and PI for 30 min at room temperature in darkness, the fluorescence was quantified by FCM at emission wavelengths of $530 \mathrm{~nm}$ and $585 \mathrm{~nm}$ within $15 \mathrm{~min}$.

\subsection{Western blot analysis}

Indicated SH-SY5Y cells were lysed in RIPA lysis buffer (Beyotime, China) which containing protease and phosphatase inhibitor (Thermo Fisher Scientific, USA). Approximately $20 \mu \mathrm{g}$ of protein was separated by $10 \%$ SDS-PAGE gel electrophoresis and then transferred to the PVDF membranes (Millipore, USA). After being blocked with $5 \%$ skim milk (Wandashan, China) overnight at $4{ }^{\circ} \mathrm{C}$, different dilution of the primary antibodies were added to incubate at room temperature for $2 \mathrm{~h}$, as followed Apaf-1 (1:200)(Santa, USA), Caspase-9 (1:1000)(CST, USA), Caspase-3 (1:1000)(CST, USA), Cleaved-Caspase-3 (1:1000) (CST, USA), Cyt C (1:1000)(CST, USA), PARP (1:1000)(CST, USA), Cleaved-PARP (1:1000)(CST, USA), AIF (1:1000)(CST, USA), VDAC1 (1:1000)(CST, USA), SOD2 (1:1000)(CST, USA). Membranes were then incubated with the corresponding HRP-conjugated secondary antibodies (1:5000) (CST, USA) at room temperature for $1 \mathrm{~h}$. After washing three times with TBST, the antibody-bound proteins were detected using the ECL chemiluminescence reagent (Yeasen, China) by Chemiluminescence gel imaging system (Tanon, China).

\subsection{Statistical analysis}

Data were expressed as the mean \pm SEM. All data were obtained from three independent experiments. Comparisons among groups were analyzed using one-way analysis (ANOVA) of variance followed by Statistical Program for Social Sciences (SPSS) software, version 24.0 (IBM Corporation, Armonk, NY, USA). $P<0.05$ was considered statistically significant.

\section{Results}

\subsection{Effect of MeHg on cell viability}

SH-SY5Y cells were exposed to different concentrations of MeHg for $3,6,12$, and $24 \mathrm{~h}$ respectively, and the relationship between cell survival rate and $\mathrm{MeHg}$ concentration and time was observed. As shown in Fig. 1, MTT results showed that the effect of MeHg on the activity of SH-SY5Y cells decreased in a concentration and time-dependent manner. After $3 \mathrm{~h}$ exposure to $\mathrm{MeHg}$, the cell survival rate showed an upward trend. Only the highest dose group had a lower cell survival rate than the control group, but there was no significant difference. After $6 \mathrm{~h}$ of exposure to $\mathrm{MeHg}$, the cell survival rate decreased gradually with the increase of the exposure dose. The $1.0 \mu \mathrm{g} / \mathrm{mL}$ group had a significant decrease compared with the control group. After exposed to MeHg for $12 \mathrm{~h}$, the 0.1 and $1.0 \mu \mathrm{g} / \mathrm{mL}$ groups decreased significantly compared with the control group. The cell survival rate of $0.1 \mu \mathrm{g} / \mathrm{mL}$ group decreased to $60 \%$ after $24 \mathrm{~h}$ treatment, which was statistically significant compared with the control group. The $24 \mathrm{~h}$ survival rate of $1.0 \mu \mathrm{g} / \mathrm{mL}$ group was only $23 \%$. Therefore, the $0.1 \mu \mathrm{g} / \mathrm{mL}$ of $\mathrm{MeHg}$ over $24 \mathrm{~h}$ was selected for the experiment of adding inhibitors groups. 


\subsection{Morphological changes of SH-SY5Y cells induced by $\mathrm{MeHg}$}

SH-SY5Y cells were treated with different concentrations of MeHg for $24 \mathrm{~h}$. The morphology of cells was observed under optical microscope (Fig. S1). The cells in the control group adhered well and grew densely in spindle shape. In the experimental groups, the growth of cells was slow, the number of cells decreased, and the gap between cells became wider. With the increase of the concentration of MeHg, part of the cells contracted and became round and bright, some cells fell off, and a small amount of cell fragments were observed. When the concentration of MeHg reached $1.0 \mu \mathrm{g} / \mathrm{mL}$, the cells presented extensive necrosis.

\subsection{Detection of intracellular ROS induced by $\mathrm{MeHg}$}

Fluorescence microscope observation and FCM were used to detect the ROS level of SH-SY5Y cells. The results in Fig. S2 show that ROS is almost undetectable in the control group. As the exposure concentration of MeHg increases, the green fluorescence labeled with the DCFH-DA probe gradually increases and strengthens, indicating a gradual increase in the release of ROS. The results of FCM showed that with the increase of the methylmercury exposure dose, the peak shifted to the right, and the ROS activity of SH-SY5Y cells gradually increased (Fig. 2a), and the ROS levels of the $0.01,0.1$ and 1.0 $\mu \mathrm{g} / \mathrm{mL}$ dose groups significantly increased $(P<0.05)$.

\subsection{Detection of intracellular $\mathrm{Ca}^{2+}$ induced by $\mathrm{MeHg}$}

The change of intracellular $\mathrm{Ca}^{2+}$ level was detected by FCM with Fluo-3 probe labeling method. As shown in Fig. 2b, the intracellular $\mathrm{Ca}^{2+}$ content of SH-SY5Y cells increased with the increase of MeHg exposure dose. Compared with the control group, the $\mathrm{Ca}^{2+}$ levels of $0.0001,0.001$ and $0.01 \mu \mathrm{g} / \mathrm{mL}$ groups increased slightly but there were not statistically significant, as that in 0.1 and $1.0 \mu \mathrm{g} / \mathrm{mL}$ groups had significantly differences, especially in the $1.0 \mu \mathrm{g} / \mathrm{mL}$ group $(P<0.01)$.

\subsection{Effect of $\mathrm{MeHg}$ on cell apoptosis}

Western blot method was performed to test the apoptosis related proteins at protein level. The expressions of Apaf-1, Caspase- 9 and Cyt C, which were the caspase-dependent apoptotic pathway related proteins, were all up-regulated with the increase of $\mathrm{MeHg}$ dose, and there were statistically differences compared with the control group (Fig. 3a, b). And the expression of Caspase-3 cleavage fragment was increased (Fig. 3c). At the same time, the expressions of PARP and AIF were up-regulated along with the increase of MeHg concentration, and PARP protein was activated in the meantime (Fig. 3df). Bax and Bcl-XL are pro-apoptotic protein and antiapoptotic protein in BCL family, respectively. The ratio of Bax and Bcl-xL increased with the increase of $\mathrm{MeHg}$ concentration (Fig. 3h). Mitochondrial damagerelated protein VDAC1 and antioxidant protein SOD2 both showed an upward trend (Fig. 3g). In addition. flow cytometry and double staining of Annxin-V/PI were used to detect the apoptosis caused by MeHg. The results showed that, as predicted, the apoptosis rate increased with the increase of exposure dose 
after $24 \mathrm{~h}$ of exposure to $\mathrm{MeHg}$ and the apoptosis rates of 0.1 and $1.0 \mu \mathrm{g} / \mathrm{mL}$ groups were statistically significant compared with the control group (Fig. S3).

\subsection{Effects on apoptosis after inhibiting ROS induction}

To ascertain whether ROS production was associated with MeHg induced apoptosis in nerve cells, $\mathrm{SH}$ SY5Y cells were treated with $0.1 \mu \mathrm{g} / \mathrm{mL}$ MeHg in the absence or presence of antioxidant NAC with detecting the levels of intracellular ROS. First, the MTT method was used to test the toxicity of NAC and its effect on damaged cells. The results of Fig. S4a showed that the cell survival rate of $0.1 \mu \mathrm{g} / \mathrm{mL} \mathrm{MeHg}$ group was significantly lower than that of the control group, reaching $52.0 \%(P<0.01)$. Due to the uneffect results on cell survival treated with $7.5 \mu \mathrm{M}$ NAC alone for $24 \mathrm{~h}$, we chose $7.5 \mu \mathrm{M}$ of NAC to pretreat the cells for $1 \mathrm{~h}$, and then $0.1 \mu \mathrm{g} / \mathrm{mL}$ MeHg was incubated for another $24 \mathrm{~h}$. The results indicated that the cell survival rate was $84.0 \%$, which was significantly higher than that of the $\mathrm{MeHg}$ alone treatment group $(P<0.01)$. Corresponding results were obtained by detecting the apoptosis rate. The total apoptosis rate of the NAC pretreatment group was lower than that of the MeHg alone treatment group (Fig. S4b). The results in Figure. S4c indicated that NAC effectively inhibited the production of intracellular ROS caused by MeHg. Then the effect of ROS inhibition on cell apoptosis was detected from the protein level. The experiment included the control group, MeHg group, NAC group, NAC + MeHg group, and the results showed that the expression of apoptosis related proteins in the $\mathrm{MeHg}$ group was significantly higher than that of the control group (Fig. 4a). Compared with the MeHg group, the expression of apoptosis related proteins in the MeHg pretreated with NAC group was changed to different degrees. The expression of PARP cleavage fragments decreased significantly, and there were no significant changes in AIF among the groups (Fig. 4b). The expressions of Caspase-3, Caspase-9, Apaf-1 and Cyt C in NAC pretreatment group was down-regulated compared with that in MeHg group (Fig. 4c, d).

\subsection{PARP/AIF signaling plays a key role in SH-SY5Y cells apoptosis induced by $\mathrm{MeHg}$}

To investigate the role of PARP/AIF in the process of apoptosis, the PARP inhibitor olaparib and the caspase pan-spectrum inhibitor Z-VAD-FMK were used in this study. MTT results showed that the cell survival rate of the MeHg group was significantly lower than that of the control group $(P<0.01)$. Z-VADFMK and olaparib alone were not toxic to the cells. Z-VAD-FMK and olaparib pretreated the cells before incubating with $\mathrm{MeHg}$, devoted the results that the cell survival rate were significantly improved in the groups compared with the MeHg group alone $(P<0.01)$ (Fig. S4a). Fig. S4b showed that Z-VAD-FMK and olaparib reduced the increase in the total apoptosis rate of SH-SY5Y cells caused by MeHg by detecting the apoptosis rate. In other words that the two inhibitors had protective effects on the damaged cells. In addition, western blot results showed that Z-VAD-FMK effectively inhibited the expression of caspase pathway related proteins, but the activation of PARP and the expression of AIF did not change significantly, indicating that the activation of PARP/AIF signal was independent of caspase signal pathway (Fig. 5a-d). After using olaparib, the activation of PARP was inhibited and the expression of AIF 
was down regulated. Interestingly, the expression of caspase related proteins Caspase- 9 and Cyt C were also significantly decreased, and the activation of Caspase-3 was inhibited (Fig. 5e-h). The inhibition of PARP might has a certain effect on caspase pathway.

\section{Discussion}

$\mathrm{MeHg}$ has been a kind of dangerous environmental contaminant, since the sensational outbreak of Minamata Disease in Japan in 1956. The researchers have never stopped studying the toxicity of MeHg. At present, a large number of population data and experimental studies have confirmed that MeHg can cause serious and irreversible nervous system damage (Harada, 1995; Wu et al., 2020). There are also in vitro studies showing that MeHg has a certain toxic effect on Neuro-2a, F3, C17.2, neural stem cells and other nerve cells, and can induce cell death through a variety of ways (Chang et al., 2013; Sato et al., 2020), but the mechanisms are still not very clear. The Caspase-dependent pathway is a classic apoptosis signaling pathway. In recent years, studies have found that PARP related signaling molecules also play a key role in the process of cell apoptosis (Wang, et al., 2016). In this study, SH-SY5Y cells were used as the target cells. In this study, we explored the role and mechanism of PARP/AIF signaling molecules in the process of apoptosis that induced by MeHg in SH-SY5Y cells, and revealed the influence of ROS on the activation of downstream apoptosis signaling molecules.

Cell viability and morphology are important indicators of cell state. This study confirmed the toxic effect of MeHg on SH-SY5Y cells. With the increase of the time and dose of MeHg, the cell viability decreased significantly. Among them, the survival rate of the highest dose group treated for $24 \mathrm{~h}$ was even lower than $50 \%$, while the low-dose groups could promote cell growth in a short time, which might be due to the bactericidal effect of $\mathrm{MeHg}$. Chang et al. detected that the $48 \mathrm{~h}$ survival rate of human NSCs cells treated with MeHg decreased slightly (Chang, et al., 2013). Chung et al. observed that the 24 h survival rate of Neuro-2a cells treated with MeHg decreased significantly (Chung et al., 2019). In this study, we found that the $24 \mathrm{~h}$ survival rate of SH-SY5Y cells treated with MeHg reached $30 \%$. Nerve cells were more sensitive to toxic substances than other cells. It was confirmed that SH-SY5Y cells decreased with MeHg in a time and dose-dependent manner. At the same time, we further confirmed the strong toxicity of MeHg in cell morphology. Under the light microscope, with the increase of MeHg concentration, the cell morphology changed significantly, and finally fell off or even died.

The role of ROS in DNA damage response is multifaceted and pleomorphic (Srinivas, et al., 2019). In previous studies, it was confirmed that there was also ROS accumulation during the apoptosis of $\mathrm{SH}$ SY5Y cells induced by silica nanoparticles (Yang et al., 2017). It can be seen that ROS plays a major role in cell survival and apoptosis. Therefore, it is predicted that reducing ROS production by using inhibitors may affect the outcome of cell apoptosis. In many cases, the production of ROS is accompanied by the increase of $\mathrm{Ca}^{2+}$. ROS and $\mathrm{Ca}^{2+}$ can accelerate the process of apoptosis and participate in a variety of apoptosis pathways. The increase of ROS was detected in SH-SY5Y cells treated with MeHg only for $3 \mathrm{~h}$, and even after 30 min of DCFH-DA staining, the green fluorescence increased in MeHg group, but hardly detected in the control group. The concentration of $\mathrm{Ca}^{2+}$ also increased after $24 \mathrm{~h}$. In addition to the 
accumulation of ROS, in previous studies, it was believed that the toxicity of cells would lead to ER stress and unfolded protein reaction (Hou et al., 2021). Through the detection of mitochondrial damage related proteins VDAC1 and SOD2, it was found that there was a dose-dependent relationship between the expression of these proteins and the concentration of $\mathrm{MeHg}$. This study confirmed that $\mathrm{MeHg}$ can induce oxidative stress in cells, increase intracellular ROS and $\mathrm{Ca}^{2+}$ level, cause mitochondrial damage and lead to apoptosis.

In order to further explore the molecular mechanism of apoptosis, we detected the apoptosis pathway related proteins. Caspase dependent apoptosis signaling pathway is one of the classic apoptosis pathways (Shi, 2002). Caspase-9, Apaf- 1 and Cyt $C$ together form an apoptotic complex to induce apoptosis. This study found that after MeHg treated cells for $24 \mathrm{~h}$, the related proteins of the pathway were activated, and the formation of apoptotic complex further activated the downstream apoptosis signal molecule Caspase-3 to form cleavage fragment, which finally led to apoptosis. These results suggest that MeHg induces apoptosis of SH-SY5Y cells through classical caspase dependent apoptosis pathway. In recent years, studies have found that there is another key signal in the process of apoptosis, namely PARP. PARP is a DNA damage repair enzyme. It is activated by recognizing DNA fragments with structural damage and is generally considered as a receptor of apoptosis. PARP and the apoptosis inducing factor AIF released from mitochondrial endomembrane can promote apoptosis (Jang et al., 2017; Regdon et al., 2019). This pathway often occurs in the brain and nervous tissues and other tissues with high metabolism. Yu et al. found that PARP was activated in mouse embryonic fibroblasts treated with DNA alkylating agent MNNG, and then AIF transferred from mitochondria to nucleus, resulting in cell apoptosis (Yu, et al., 2002). AlF was considered to be a completely independent and caspase independent active factor with apoptotic effect at the initial stage of discovery. However, many studies have shown that AIF is a double-edged sword, which can not only participate in the oxidative phosphorylation and respiratory chain circulation of normal cells, but also can release from mitochondria and induce nucleus lysis leading to apoptosis (Murari et al., 2020; Nan et al., 2020). Through the detection of PARP and AIF proteins, we found that PARP/AIF pathway was also activated in the process of SH-SY5Y cell apoptosis induced by $\mathrm{MeHg}$. These results confirmed that $\mathrm{MeHg}$ could induce apoptosis at least through caspase and PARP/AIF pathways. At the same time, the proportion of pro-apoptotic protein Bax and anti-apoptotic protein $\mathrm{Bcl}-\mathrm{xL}$ increased, indicating the outcome of $\mathrm{MeHg}$ inducing apoptosis.

This study is the first time to explore the role of ROS in apoptosis and the relationship between caspase and PARP/AIF apoptosis pathway through three intervention methods. Firstly, by inhibiting the generation of ROS, the role of ROS in activating downstream apoptotic pathways was discussed, NAC has been widely used in clinic because it can effectively inhibit oxidative stress (Halasi et al., 2013; Luczak and Zhitkovich, 2013; Rushworth and Megson, 2014). Fluorescence analysis results showed that NAC could effectively inhibit the generation of ROS. The apoptosis rate of the MeHg and NAC co-incubation group was significantly lower than that of the MeHg group. On this basis, apoptosis related proteins were detected, and it was found that the expressions of these proteins decreased to varying degrees in the NAC and $\mathrm{MeHg}$ co-incubation group compared with the MeHg alone group. In general, the reduction of ROS 
has a certain regulatory effect on apoptosis, but it seems that it cannot completely inhibit the occurrence of apoptosis. It indicates that the downstream apoptotic signal molecules are still functioning at the same time or one of them. So which signal plays the main role, we choose to add inhibitors to explore. ZVAD-FMK is a pan-Caspase inhibitor that can inhibit the function of Caspase 1-10 proteins (Martinet et al., 2006; Moretti et al., 2009). The reason is that fluoromethyl ketone derived peptides can effectively mimic the caspase cleavage site, so that Z-VAD-FMK can bind to the caspase catalytic site and inhibit the induction of apoptosis. Studies in vivo have shown that the administration of Z-VAD-FMK was not toxic and could inhibit apoptosis in animal models (Xu et al., 2019). Our experiments also confirmed that ZVAD-FMK could inhibit the increase in apoptosis rate of SH-SY5Y cells caused by MeHg, effectively reduced the expression of Caspase-3, 9 and Cyt C, and blocked the caspase pathway. However, Z-VADFMK had little effect on PARP activation and AIF expression. That is to say, MeHg can still cause SHSY5Y cell apoptosis after using pan-Caspase inhibitors, indicating that the activation of PARP/AIF signal is independent of caspase dependent apoptosis pathway. On the contrary, whether the inhibition of the PARP/AIF pathway will affect the activation of caspase apoptotic signal needs further study. In this study, the use of olaparib effectively reduced the increase of the apoptosis rate induced by MeHg, the expression of PARP and its cleavage fragments and AIF protein were inhibited. Interestingly, we also detected caspase related proteins and found that olaparib meanwhile inhibited the expressions of Caspase-3 activation fragments, Caspase -9 and Cyt $C$ proteins. It is speculated that the activation of PARP/AIF signal plays an important role in ROS mediated apoptosis of SH-SY5Y cells induced by MeHg, which is independent of caspase dependent apoptosis pathway, but affects caspase dependent apoptosis pathway (Fig. 6). It shows that the PARP/AIF apoptotic signal plays a major role in the apoptosis process of SH-SY5Y caused by MeHg.

\section{Conclusions}

MeHg has a toxic effect on $\mathrm{SH}-\mathrm{SY} 5 \mathrm{Y}$ cells. It activates downstream apoptotic signaling pathways through oxidative stress and mitochondrial damage, including PARP/AIF pathway and caspase-3 apoptotic complex pathway. After the intervention of ROS generation, it was found that ROS, as an upstream apoptotic signal molecule, can regulate the downstream apoptotic signal pathway. But it can not completely inhibit the occurrence of apoptosis. The function of PARP/AIF pathway does not depend on caspase, but has different effects on the expression of caspase related proteins. Blocking caspase-3 pathway could reduce the apoptosis rate of SH-SY5Y cells, but could not inhibit the expression of PARP / AIF protein. These results indicate that there is a relationship between the two apoptotic pathways, and provide a basis for further study of the molecular mechanism. At present, there are relatively few reports on the relationship between these two apoptotic pathways and the joint study with ROS. This study provides a new idea for exploring the mechanism of SH-SY5Y cell apoptosis induced by $\mathrm{MeHg}$ and the selection of therapeutic drugs for MeHg poisoning.

\section{Declarations}


Author Contribution Shanshan Hou: performed the experiments, Formal analysis, Writing - original draft. Xiayu Zhang: performed the experiments, Formal analysis, Validation. Xiaofan Ning and Hao Wu: Investigation, Data curation. Xinyue Li and Kai Ma: Software, Formal analysis. Huifang Hao and Chunrui Li: Methodology. Chunping Lv: Supervision. Zhongjun Du: Conceptualization, Project administration. Haiying Du: Supervision, Resources. Minghua Jin: Conceptualization, Project administration, Funding acquisition.

Funding This work was supported by fund from the National Natural Science Foundation of China (No. 30771777). The authors gratefully acknowledge the fund supports.

Data Availability The datasets generated during and/or analysed during the current study are available from the corresponding author on reasonable request.

Ethics Approval and Consent to Participate Not applicable.

Consent for Publication Written informed consent for publication was obtained from all participants.

Competing Interests The authors declare no competing interests.

\section{References}

1. Artus, C., Boujrad, H., Bouharrour, A., Brunelle, M. N., Hoos, S., Yuste, V. J., Lenormand, P., Rousselle, J. C., Namane, A., England, P., Lorenzo, H. K. and Susin, S. A., 2010. AlF promotes chromatinolysis and caspase-independent programmed necrosis by interacting with histone H2AX. EMBO J.29. 15851599. https://doi.org/10.1038/emboj.2010.43.

2. Bano, D. and Prehn, J. H. M., 2018. Apoptosis-Inducing Factor (AIF) in Physiology and Disease: The Tale of a Repented Natural Born Killer. EBioMedicine.30. 29-37. https://doi.org/10.1016/j.ebiom.2018.03.016.

3. Caito, S. W. and Aschner, M., 2016. NAD+ Supplementation Attenuates Methylmercury Dopaminergic and Mitochondrial Toxicity in Caenorhabditis Elegans. Toxicol Sci.151. 139-149. https://doi.org/10.1093/toxsci/kfw030.

4. Cariccio, V. L., Sama, A., Bramanti, P. and Mazzon, E., 2019. Mercury Involvement in Neuronal Damage and in Neurodegenerative Diseases. Biol Trace Elem Res.187. 341-356. https://doi.org/10.1007/s12011-018-1380-4.

5. Chang, S. H., Lee, H. J., Kang, B., Yu, K. N., Minai-Tehrani, A., Lee, S., Kim, S. U. and Cho, M. H., 2013. Methylmercury induces caspase-dependent apoptosis and autophagy in human neural stem cells. $J$ Toxicol Sci.38. 823-831. https://doi.org/10.2131/jts.38.823.

6. Chung, Y. P., Yen, C. C., Tang, F. C., Lee, K. I., Liu, S. H., Wu, C. C., Hsieh, S. S., Su, C. C., Kuo, C. Y. and Chen, Y. W., 2019. Methylmercury exposure induces ROS/Akt inactivation-triggered endoplasmic reticulum stress-regulated neuronal cell apoptosis. Toxicology.425. 152245.

https://doi.org/10.1016/j.tox.2019.152245.

Page 12/21 
7. Farina, M., Aschner, M. and Rocha, J. B., 2011. Oxidative stress in MeHg-induced neurotoxicity. Toxicol Appl Pharmacol.256. 405-417. https://doi.org/10.1016/j.taap.2011.05.001.

8. Halasi, M., Wang, M., Chavan, T. S., Gaponenko, V., Hay, N. and Gartel, A. L., 2013. ROS inhibitor Nacetyl-L-cysteine antagonizes the activity of proteasome inhibitors. Biochem J.454. 201-208. https://doi.org/10.1042/BJ20130282.

9. Harada, M., 1995. Minamata disease: methylmercury poisoning in Japan caused by environmental pollution. Crit Rev Toxicol.25. 1-24. https://doi.org/10.3109/10408449509089885.

10. Hou, S., Zhang, X., Du, H., Ning, X., Wu, H., Li, C., Liu, Y., Sun, Z., Du, Z. and Jin, M., 2021. Silica nanoparticles induce mitochondrial pathway-dependent apoptosis by activating unfolded protein response in human neuroblastoma cells. Environ Toxicol.36. 675-685.

https://doi.org/10.1002/tox.23071.

11. Ishihara, Y., Tsuji, M., Kawamoto, T. and Yamazaki, T., 2016. Involvement of reactive oxygen species derived from mitochondria in neuronal injury elicited by methylmercury. J Clin Biochem Nutr.59. 182190. https://doi.org/10.3164/jcbn.16-19.

12. Jang, K. H., Do, Y. J., Son, D., Son, E., Choi, J. S. and Kim, E., 2017. AlF-independent parthanatos in the pathogenesis of dry age-related macular degeneration. Cell Death Dis.8. e2526. https://doi.org/10.1038/cddis.2016.437.

13. Koos, B. J. and Longo, L. D., 1976. Mercury toxicity in the pregnant woman, fetus, and newborn infant. A review. Am J Obstet Gynecol.126. 390-409. https://doi.org/10.1016/0002-9378(76)90557-3.

14. Kowalska, M., Piekut, T., Prendecki, M., Sodel, A., Kozubski, W. and Dorszewska, J., 2020. Mitochondrial and Nuclear DNA Oxidative Damage in Physiological and Pathological Aging. DNA Cell Biol.39. 1410-1420. https://doi.org/10.1089/dna.2019.5347.

15. Lu, T. H., Hsieh, S. Y., Yen, C. C., Wu, H. C., Chen, K. L., Hung, D. Z., Chen, C. H., Wu, C. C., Su, Y. C., Chen, Y. W., Liu, S. H. and Huang, C. F., 2011. Involvement of oxidative stress-mediated ERK1/2 and p38 activation regulated mitochondria-dependent apoptotic signals in methylmercury-induced neuronal cell injury. Toxicol Lett.204. 71-80. https://doi.org/10.1016/j.toxlet.2011.04.013.

16. Luczak, M. W. and Zhitkovich, A., 2013. Role of direct reactivity with metals in chemoprotection by Nacetylcysteine against chromium(VI), cadmium(II), and cobalt(II). Free Radic Biol Med.65. 262-269. https://doi.org/10.1016/j.freeradbiomed.2013.06.028.

17. Madungwe, N. B., Feng, Y., Lie, M., Tombo, N., Liu, L., Kaya, F. and Bopassa, J. C., 2018. Mitochondrial inner membrane protein (mitofilin) knockdown induces cell death by apoptosis via an AIF-PARPdependent mechanism and cell cycle arrest. Am J Physiol Cell Physiol.315. C28-C43. https://doi.org/10.1152/ajpcell.00230.2017.

18. Martinet, W., Schrijvers, D. M., Herman, A. G. and De Meyer, G. R., 2006. z-VAD-fmk-induced nonapoptotic cell death of macrophages: possibilities and limitations for atherosclerotic plaque stabilization. Autophagy.2. 312-314. https://doi.org/10.4161/auto.2966.

19. Moretti, L., Kim, K. W., Jung, D. K., Willey, C. D. and Lu, B., 2009. Radiosensitization of solid tumors by Z-VAD, a pan-caspase inhibitor. Mol Cancer Ther.8. 1270-1279. https://doi.org/10.1158/1535- 
7163.MCT-08-0893.

20. Murari, A., Rhooms, S. K., Goparaju, N. S., Villanueva, M. and Owusu-Ansah, E., 2020. An antibody toolbox to track complex I assembly defines AIF's mitochondrial function. J Cell Biol.219. https://doi.org/10.1083/jcb.202001071.

21. Nan, L., Xie, Q., Chen, Z., Zhang, Y., Chen, Y., Li, H., Lai, W., Chen, Y. and Huang, M., 2020. Involvement of PARP-1/AIF Signaling Pathway in Protective Effects of Gualou Guizhi Decoction Against Ischemia-Reperfusion Injury-Induced Apoptosis. Neurochem Res.45. 278-294. https://doi.org/10.1007/s11064-019-02912-3.

22. Nedungadi, D., Binoy, A., Vinod, V., Vanuopadath, M., Nair, S. S., Nair, B. G. and Mishra, N., 2021. Ginger extract activates caspase independent paraptosis in cancer cells via ER stress, mitochondrial dysfunction, AIF translocation and DNA damage. Nutr Cancer.73. 147-159. https://doi.org/10.1080/01635581.2019.1685113.

23. Nogara, P. A., Oliveira, C. S., Schmitz, G. L., Piquini, P. C., Farina, M., Aschner, M. and Rocha, J. B. T., 2019. Methylmercury's chemistry: From the environment to the mammalian brain. Biochim Biophys Acta Gen Subj.1863. 129284. https://doi.org/10.1016/j.bbagen.2019.01.006.

24. Pereira, L. C., de Paula, E. S., Pazin, M., Carneiro, M. F. H., Grotto, D., Barbosa, F., Jr. and Dorta, D. J., 2020. Niacin prevents mitochondrial oxidative stress caused by sub-chronic exposure to methylmercury. Drug Chem Toxicol.43. 64-70. https://doi.org/10.1080/01480545.2018.1497045.

25. Polunas, M., Halladay, A., Tjalkens, R. B., Philbert, M. A., Lowndes, H. and Reuhl, K., 2011. Role of oxidative stress and the mitochondrial permeability transition in methylmercury cytotoxicity. Neurotoxicology.32. 526-534. https://doi.org/10.1016/j.neuro.2011.07.006.

26. Qi, Z., Dong, W., Shi, W., Wang, R., Zhang, C., Zhao, Y., Ji, X., Liu, K. J. and Luo, Y., 2015. Bcl-2 phosphorylation triggers autophagy switch and reduces mitochondrial damage in limb remote ischemic conditioned rats after ischemic stroke. Transl Stroke Res.6. 198-206. https://doi.org/10.1007/s12975-015-0393-y.

27. Regdon, Z., Robaszkiewicz, A., Kovacs, K., Rygielska, Z., Hegedus, C., Bodoor, K., Szabo, E. and Virag, L., 2019. LPS protects macrophages from AIF-independent parthanatos by downregulation of PARP1 expression, induction of SOD2 expression, and a metabolic shift to aerobic glycolysis. Free Radic Biol Med.131. 184-196. https://doi.org/10.1016/j.freeradbiomed.2018.11.034.

28. Rushworth, G. F. and Megson, I. L., 2014. Existing and potential therapeutic uses for N-acetylcysteine: the need for conversion to intracellular glutathione for antioxidant benefits. Pharmacol Ther.141. 150-159. https://doi.org/10.1016/j.pharmthera.2013.09.006.

29. Sato, M., Toyama, T., Kim, M. S., Lee, J. Y., Hoshi, T., Miura, N., Naganuma, A. and Hwang, G. W., 2020. Increased putrescine levels due to ODC1 overexpression prevents mitochondrial dysfunction-related apoptosis induced by methylmercury. Life Sci.256. 118031. https://doi.org/10.1016/j.Ifs.2020.118031.

30. Shi, Y., 2002. Mechanisms of caspase activation and inhibition during apoptosis. Mol Cell.9. 459470. https://doi.org/10.1016/s1097-2765(02)00482-3. 
31. Singh, A., Kukreti, R., Saso, L. and Kukreti, S., 2019. Oxidative Stress: A Key Modulator in Neurodegenerative Diseases. Molecules.24. https://doi.org/10.3390/molecules24081583.

32. Srinivas, U. S., Tan, B. W. Q., Vellayappan, B. A. and Jeyasekharan, A. D., 2019. ROS and the DNA damage response in cancer. Redox Biol.25. 101084. https://doi.org/10.1016/j.redox.2018.101084.

33. Tarafdar, A. and Pula, G., 2018. The Role of NADPH Oxidases and Oxidative Stress in Neurodegenerative Disorders. Int J Mol Sci.19. https://doi.org/10.3390/ijms19123824.

34. Wang, Y., Dawson, V. L. and Dawson, T. M., 2009. Poly(ADP-ribose) signals to mitochondrial AlF: a key event in parthanatos. Exp Neurol.218. 193-202. https://doi.org/10.1016/j.expneurol.2009.03.020.

35. Wang, Y., An, R., Umanah, G. K., Park, H., Nambiar, K., Eacker, S. M., Kim, B., Bao, L., Harraz, M. M., Chang, C., Chen, R., Wang, J. E., Kam, T. I., Jeong, J. S., Xie, Z., Neifert, S., Qian, J., Andrabi, S. A., Blackshaw, S., Zhu, H., Song, H., Ming, G. L., Dawson, V. L. and Dawson, T. M., 2016. A nuclease that mediates cell death induced by DNA damage and poly(ADP-ribose) polymerase-1. Science.354. https://doi.org/10.1126/science.aad6872.

36. Wu, P., Zakem, E. J., Dutkiewicz, S. and Zhang, Y., 2020. Biomagnification of Methylmercury in a Marine Plankton Ecosystem. Environ Sci Technol.54. 5446-5455.

https://doi.org/10.1021/acs.est.9b06075.

37. Xu, N., Hua, Z., Ba, G., Zhang, S., Liu, Z., Thiele, C. J. and Li, Z., 2019. The anti-tumor growth effect of a novel agent DMAMCL in rhabdomyosarcoma in vitro and in vivo. J Exp Clin Cancer Res.38. 118. https://doi.org/10.1186/s13046-019-1107-1.

38. Yang, Y., Yu, Y., Wang, J., Li, Y., Li, Y., Wei, J., Zheng, T., Jin, M. and Sun, Z., 2017. Silica nanoparticles induced intrinsic apoptosis in neuroblastoma SH-SY5Y cells via CytC/Apaf-1 pathway. Environ Toxicol Pharmacol.52. 161-169. https://doi.org/10.1016/j.etap.2017.01.010.

39. Yu, S. W., Wang, H., Poitras, M. F., Coombs, C., Bowers, W. J., Federoff, H. J., Poirier, G. G., Dawson, T. M. and Dawson, V. L., 2002. Mediation of poly(ADP-ribose) polymerase-1-dependent cell death by apoptosis-inducing factor. Science.297. 259-263. https://doi.org/10.1126/science.1072221.

40. Zhu, S., Zhang, Z. and Zagar, D., 2018. Mercury transport and fate models in aquatic systems: A review and synthesis. Sci Total Environ.639. 538-549.

https://doi.org/10.1016/j.scitotenv.2018.04.397.

41. Zorov, D. B., Juhaszova, M. and Sollott, S. J., 2014. Mitochondrial reactive oxygen species (ROS) and ROS-induced ROS release. Physiol Rev.94. 909-950. https://doi.org/10.1152/physrev.00026.2013.

\section{Figures}




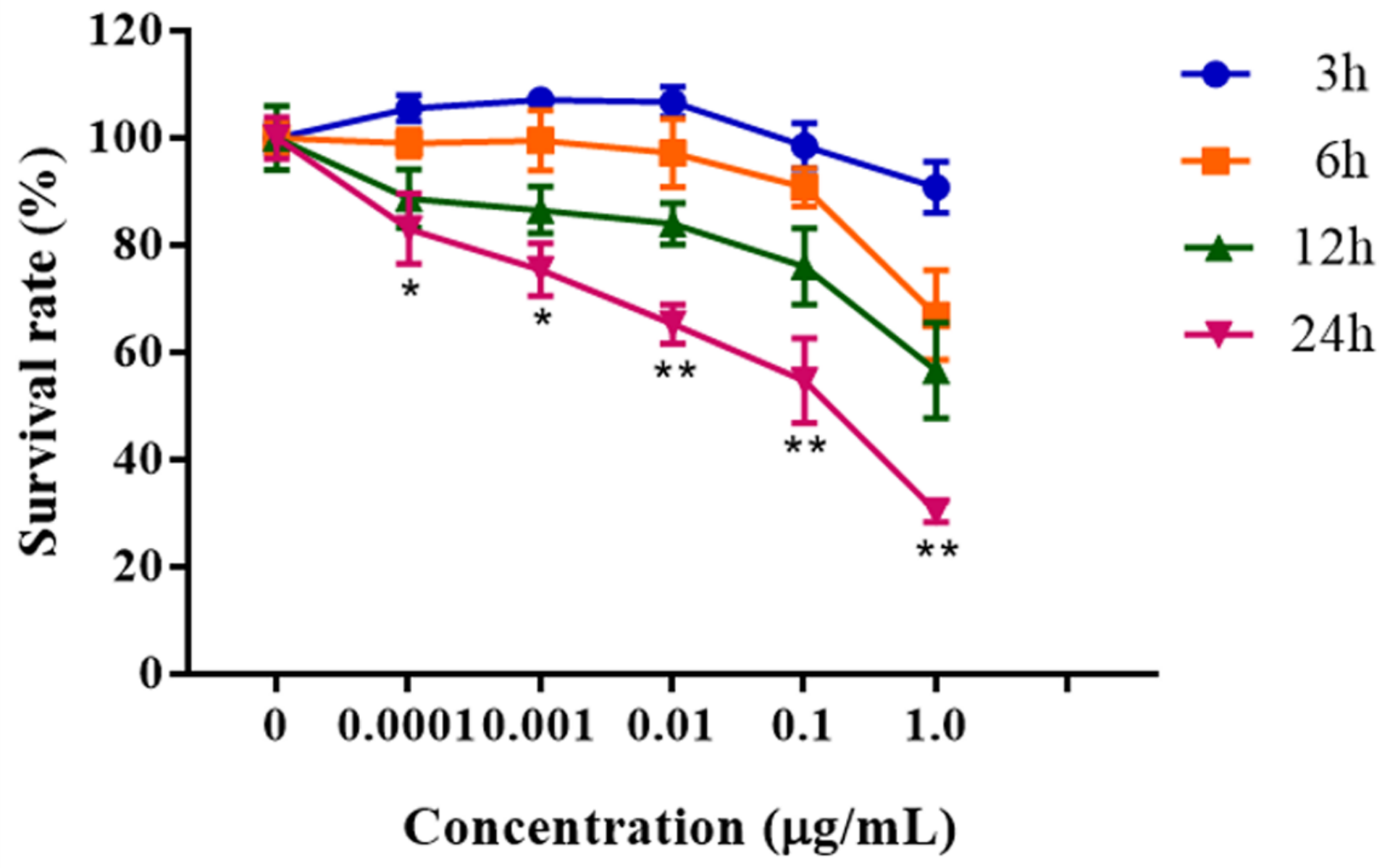

Figure 1

The effect of methylmercury on the survival rate and morphology of SH-SY5Y cells. MTT assay was used to detect the time-dose-response relationship after $\mathrm{MeHg}$ exposure. The values were presented as mean \pm SEM $(n=3)$. Significant differences with the control group were designated as * $P<0.05, * \star P<0.01$. 
a
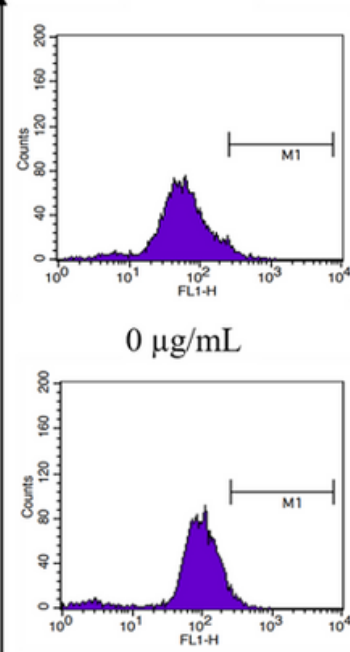

$0.01 \mu \mathrm{g} / \mathrm{mL}$

b

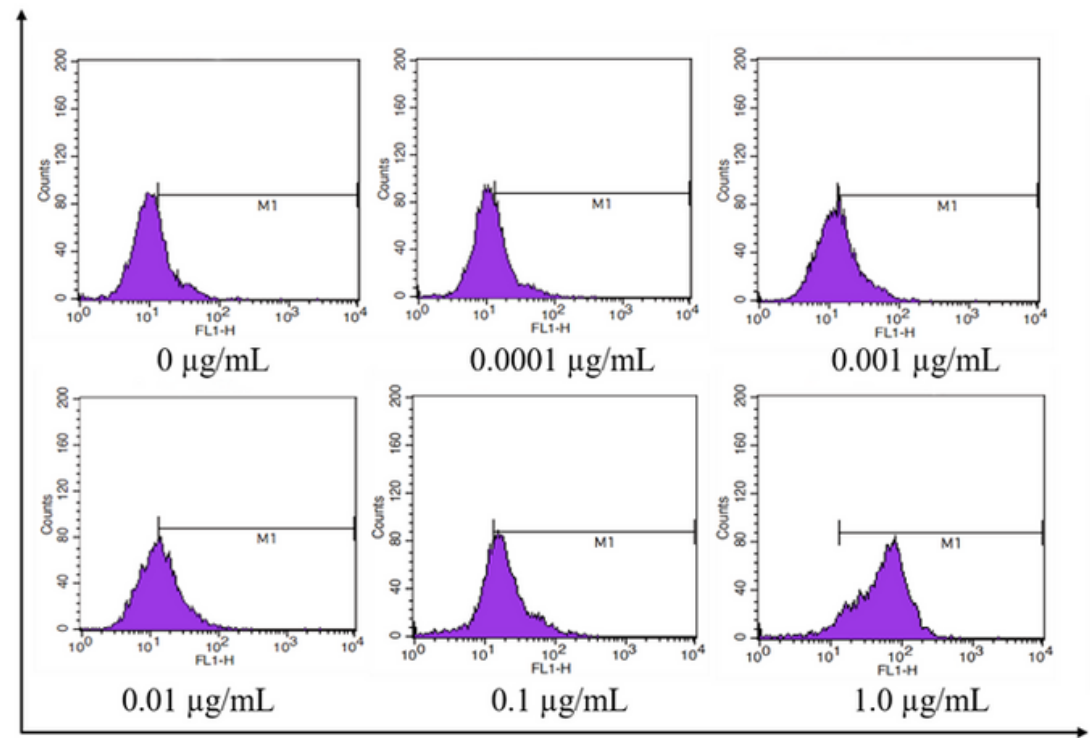

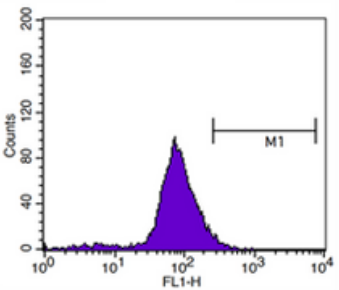

$0.001 \mu \mathrm{g} / \mathrm{mL}$

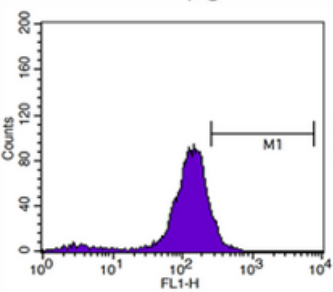

$0.1 \mu \mathrm{g} / \mathrm{mL}$

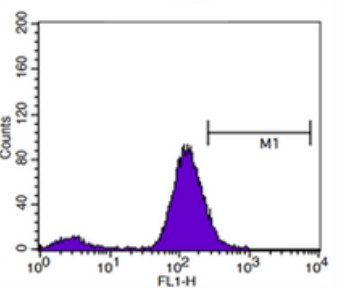

$1.0 \mu \mathrm{g} / \mathrm{mL}$

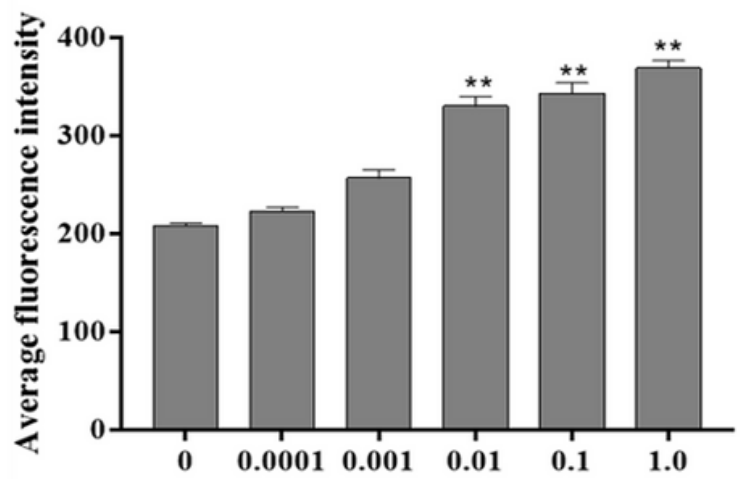

Concentration $(\mu \mathrm{g} / \mathrm{mL})$

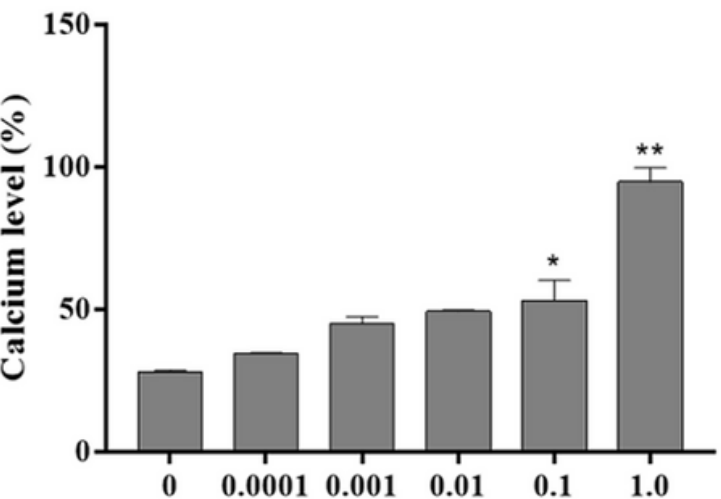

Concentration $(\mu \mathrm{g} / \mathrm{mL})$

Figure 2

The effect of MeHg on the level of ROS and Ca2+ in SH-SY5Y cells. (a) The ROS levels in cells were detected by FCM. (b) FCM to detect the effects of MeHg on intracellular Ca2+ by using single staining with Fluo-3 probe. The values were presented as mean \pm SEM $(n=3)$. Significant differences with the control group were designated as * $P<0.05$, ** $P<0.01$. 

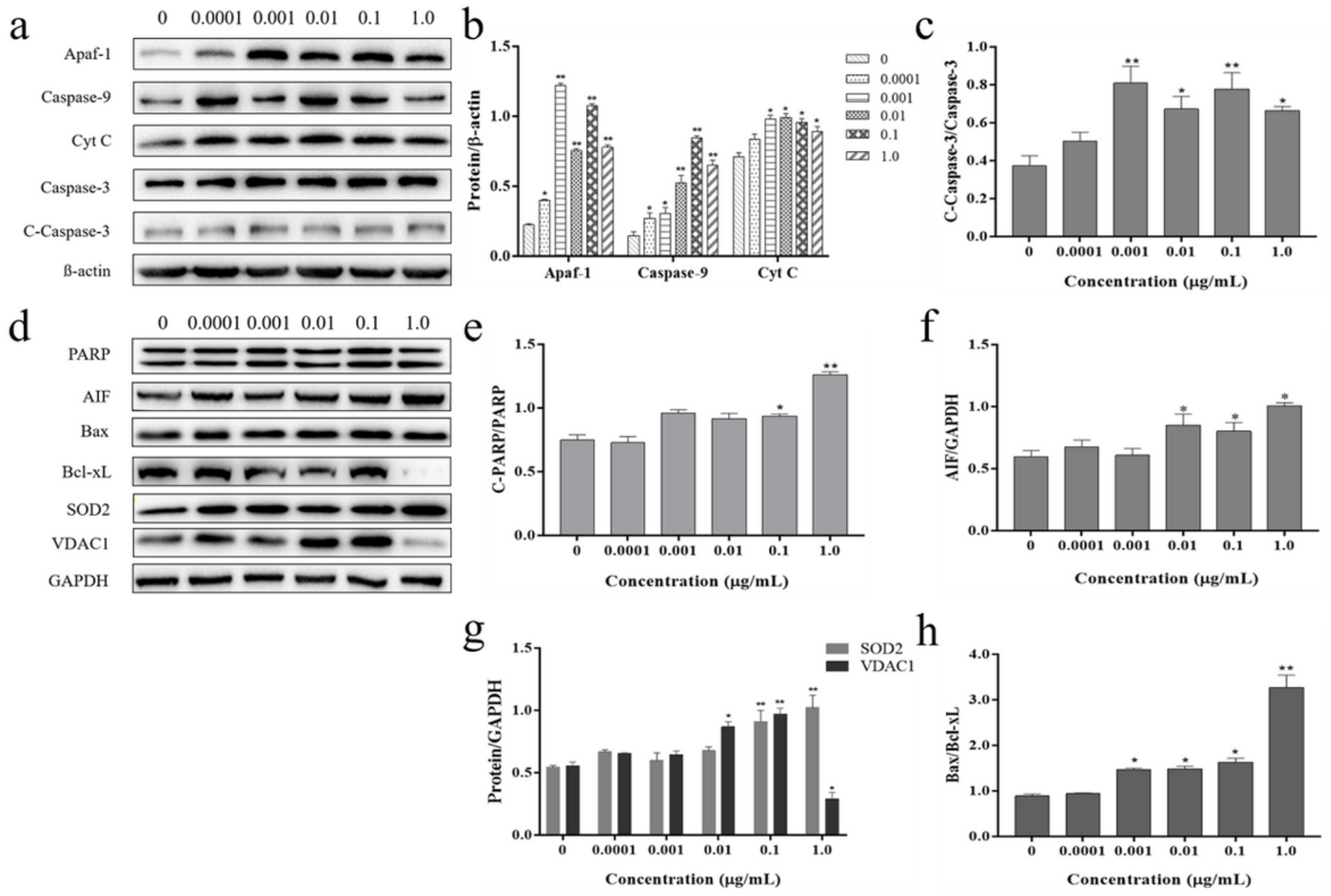

\section{Figure 3}

Expression of apoptosis related proteins in SH-SY5Y cells induced by MeHg. (a) The effects of MeHg on the expressions of Caspase pathway-related proteins in cells were detected by western blot. (b) Gray value analysis of Apaf-1, Caspase-9, Cyt C protein bands. (c) The ratio of Caspase- 3 and its activated fragment band gray value. (d) The expressions of apoptosis-related signals PARP, AIF, Bax, Bcl-xL and mitochondrial damage-related proteins VDAC1 and SOD2 in cells induced by MeHg. (e) The ratio of the gray value of PARP to its fragment. ( $f$ ) Gray value analysis of AIF protein expression. (g) VDAC1 and SOD2 band gray value analysis. (h) The ratio of the band gray value between Bax and Bcl-xL expression. The values were presented as mean \pm SEM $(n=3)$. Significant differences with the control group were designated as $* P<0.05, * * P<0.01$. 


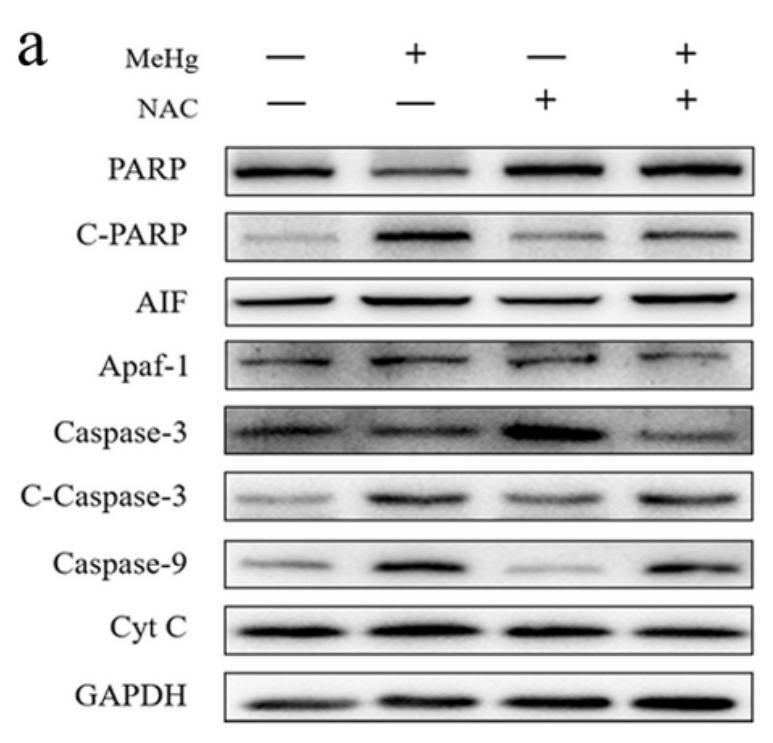

b
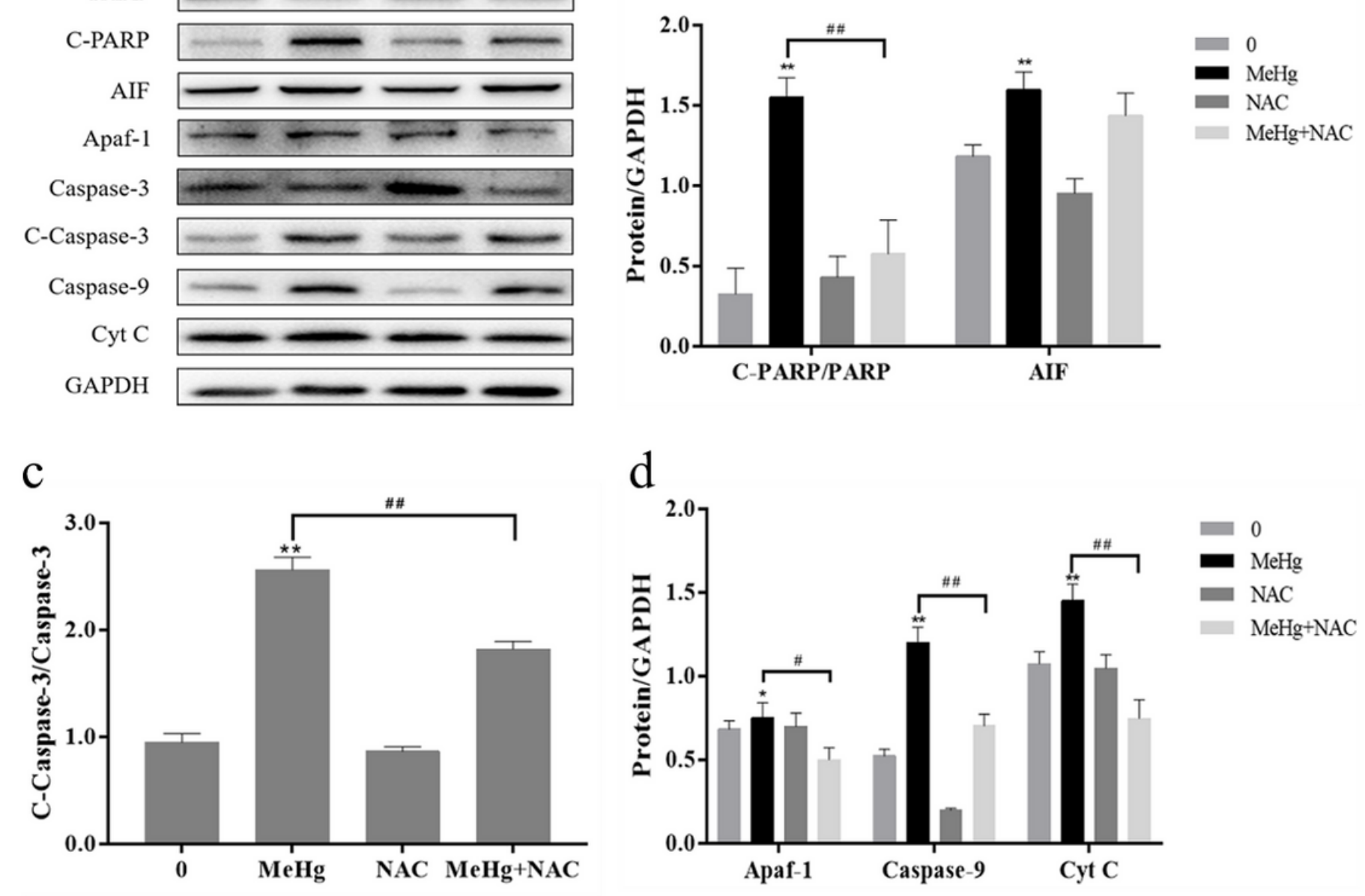

\section{Figure 4}

Inhibition of intracellular ROS on the rate of apoptosis and the expression of apoptosis-related proteins induced by MeHg. (a) SH-SY5Y cells were pretreated with ROS inhibitor NAC for $1 \mathrm{~h}$, and then incubated with $\mathrm{MeHg}$ for $24 \mathrm{~h}$. The expression of apoptosis-related proteins were detected. Groups include: the control group, NAC group, MeHg group and NAC+MeHg group. (b, c, d) Gray value analysis of apoptosisrelated protein expression bands after inhibiting ROS induction. The values were presented as mean \pm SEM $(n=3)$. * $P<0.05$, ** $P<0.01$ compared with the control group, and \# $P<0.05$, \#\# $P<0.01$ compared with group treated with $\mathrm{MeHg}$ alone. 

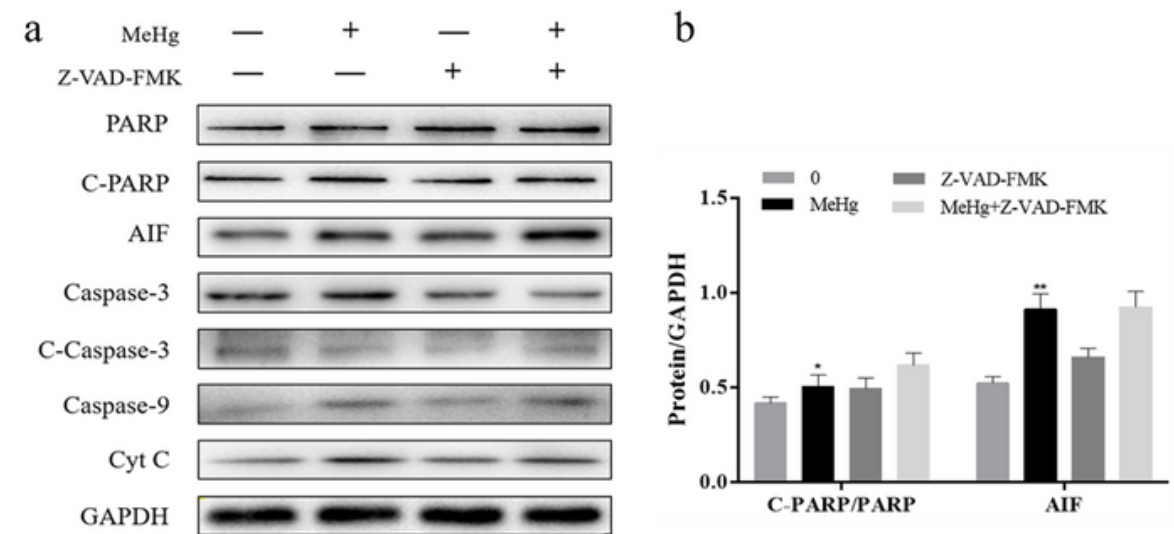

c
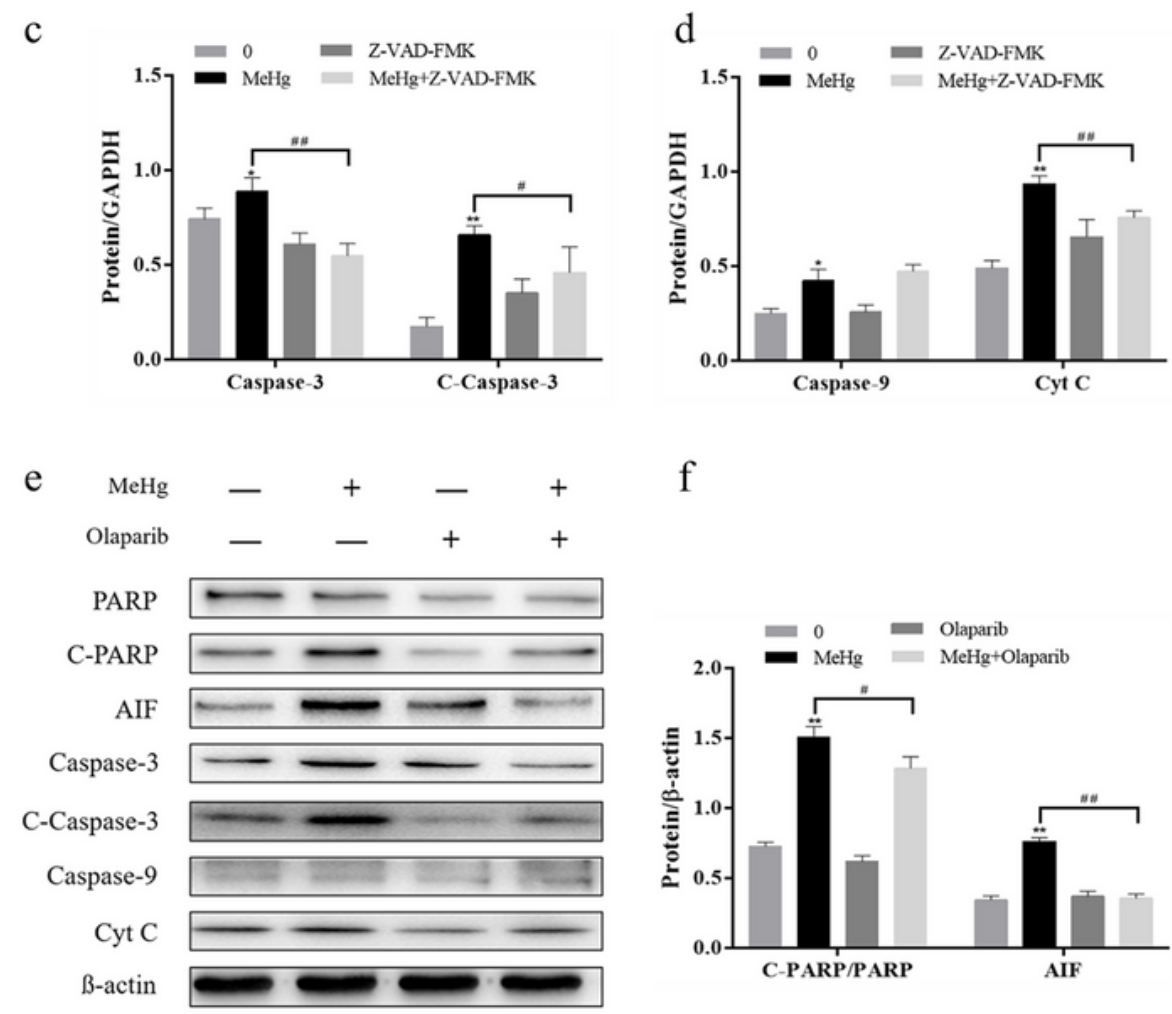

f

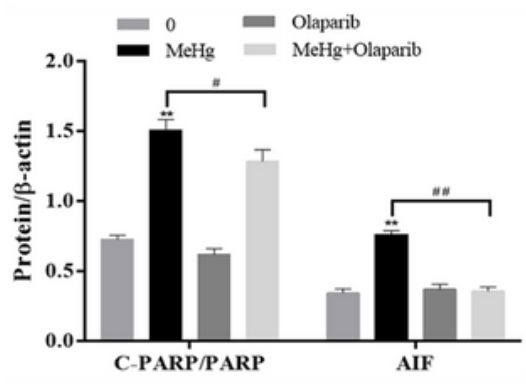

g
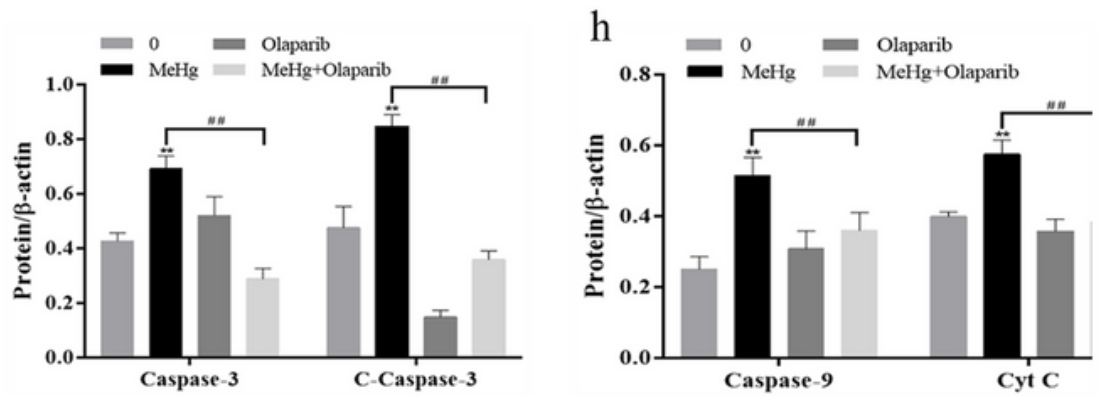

\section{Figure 5}

The effect of inhibiting caspase and PARP signaling on the expression of apoptosis related proteins induced by MeHg. (A) The expressions of apoptosis-related proteins induced by $\mathrm{MeHg}$ with or without inhibitor Z-VAD-FMK. (b, c, d) Gray value analysis of (a) protein bands. (e) The expressions of apoptosisrelated proteins induced by MeHg with or without inhibitor olaparib. $(f, g, h)$ Gray value analysis of (e) 
protein bands. The values were presented as mean \pm SEM $(n=3)$. ${ }^{*} P<0.05$, ${ }^{\star *} P<0.01$ compared with the control group, and \# $\mathrm{P}<0.05$, \#\# $\mathrm{P}<0.01$ compared with group treated with $\mathrm{MeHg}$ alone.

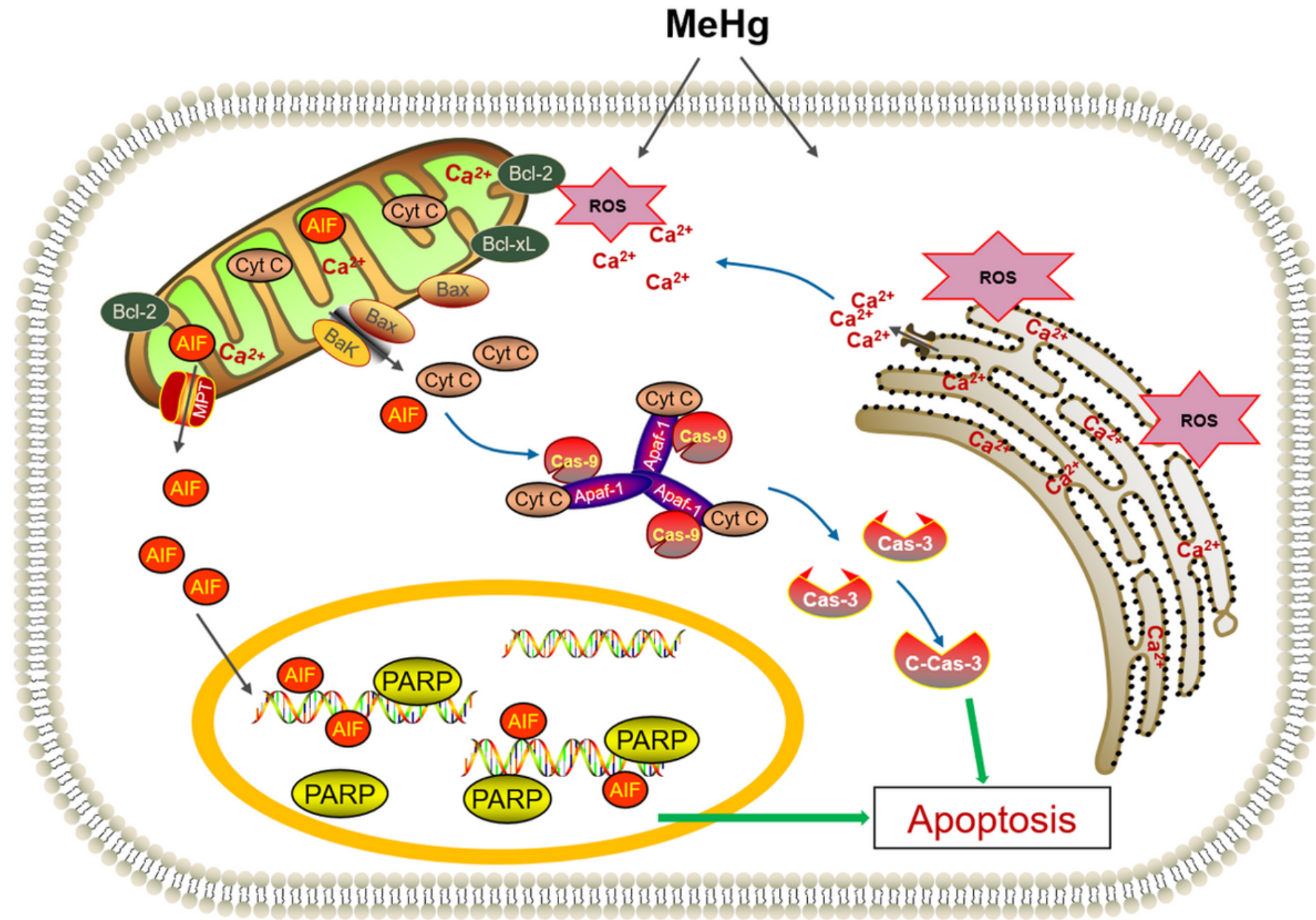

Figure 6

MeHg induces SH-SY5Y cell apoptosis prediction mechanism diagram. MeHg induces apoptosis by activating caspase and PARP / AIF pathways. There is a certain relationship and mutual influence between the two pathways.

\section{Supplementary Files}

This is a list of supplementary files associated with this preprint. Click to download.

- SupplementaryMaterial.docx 